\title{
An 'Aristotelian' Philosophy of the Internet
}

\author{
László Ropolyi \\ Eötvös University, Budapest, Hungary \\ ropolyi@gmail.com
}

\begin{abstract}
The paper argues for the necessity of building up a philosophy of the internet and proposes a version of it, an 'Aristotelian' philosophy of the internet. First, a short overview of some recent trends in the internet research is presented. This train of thoughts leads to a proposal of understanding the nature of the internet in the spirit of the Aristotelian philosophy i.e., to conceive "the internet as the internet", as a totality of its all aspects, as a whole entity. For this purpose, the internet is explained in four - easily distinguishable, but obviously connected - contexts: we regard it as a system of technology, as an element of communication, as a cultural medium and as an independent organism. Based on these investigations we conclude that the internet is the medium of a new mode of human existence created by late modern man; a mode that is built on earlier (i.e., natural, and social) spheres of existence and yet it is markedly different from them. We call this newly formed existence web-life.
\end{abstract}

\section{CCS CONCEPTS}

- General literature; • Social networks; • Public Internet;

\section{KEYWORDS}

Philosophy of the Internet, Internet Research, Internet Science, Aristotelian Philosophy, Technology, Information, Virtuality, Communication, Culture, Organism, Modes of Human Existence, Web-life

\section{ACM Reference Format:}

László Ropolyi. 2021. An 'Aristotelian' Philosophy of the Internet. In 13th ACM Web Science Conference 2021 (WebSci '21 Companion), June 21-25, 2021, Virtual Event, United Kingdom. ACM, New York, NY, USA, 5 pages. https://doi.org/10.1145/3462741.3466811

\section{INTRODUCTION}

The appearance and the extended use of the internet can probably be considered as the most significant development of the 20th century. However, this becomes evident if and only if the internet is not simply conceived as a network of interconnected computers or a new communication tool, but as a new, highly complex artificial being with a mostly unknown nature. An unavoidable task of our age is to use, shape, and, in general, discover it - and to interpret our praxis, to study and understand the internet, including all the things, relations, and processes contributing to its nature and use.

Studying the question what the internet is and its history - apparently - provides a praxis-oriented answer, see e.g., [1-4]. Based

Permission to make digital or hard copies of part or all of this work for personal or classroom use is granted without fee provided that copies are not made or distributed for profit or commercial advantage and that copies bear this notice and the full citation on the first page. Copyrights for third-party components of this work must be honored. For all other uses, contact the owner/author(s).

WebSci '21 Companion, fune 21-25, 2021, Virtual Event, United Kingdom

(c) 2021 Copyright held by the owner/author(s)

ACM ISBN 978-1-4503-8525-1/21/06.

https://doi.org/10.1145/3462741.3466811 on the social and cultural demands of the 1960s, networks of interconnected computers were built up, and for the 1980s a worldwide network of computers, the net, emerged and became widely used. From the 1990s the network of web pages, the world wide web, has been built on the net. Using the possibilities provided by the coexisting net and web, social networks (such as Facebook) have been created since the 2000 s. Nowadays, networking of connected physical vehicles, the emergence of the internet of things, the IoT, seems to be an essential new development. Besides these networks there is a regularly renewed activity to form sharing networks to share 'contents' (files, material and intellectual property, products, knowledge, services, events, human abilities, etc.) using, e.g., streaming or peer-to-peer technologies. In this way, currently, from a practical point of view, the internet can essentially be identified as a complex being formed from five kinds of intertwined coexisting networks: the net, the web, the social networks, the IoT, and the sharing networks. Taking into account these coexisting networks it seems to be reasonable to seek for a theoretical or philosophical description of this complex being instead of one or other parts of it.

\section{THEORETICAL VS. PHILOSOPHICAL DESCRIPTION OF THE INTERNET}

Among researchers of the internet there is a lack of consensus regarding how to best describe the internet theoretically, i.e., whether it is a (scientific) theory or rather a philosophy of the internet that is needed. Scientific theories on the internet presuppose that the internet is an independent entity of our world and seek for its specific theoretical understanding and description. Because of the complexity of the internet, it is not surprising that comparing these theories to the classical scientific theories have a definite trans-, inter-, or multidisciplinary character. They usually combine the methodological and conceptual apparatus of social-scientific (sociology, psychology, political theory, law, political economy, anthropology, etc.), scientific, mathematical, and engineering (theory of networks, theory of information, computing, etc.) disciplines to create a proper 'internet scientific' conceptual framework and methodology. Some of these theories really fit into a recent scientific standard providing universally valid knowledge in the form of justifiable or refutable statements, with empirical background and philosophical foundations. Their empirical background frequently includes disciplinary or studies-origin facts, and their philosophical foundations vary case by case. (Some additional methodological considerations on the internet research can be found in [4].)

Although there is no universally accepted theory of the internet: there is no consensus about the fundamental specificities of the internet. In other words, the philosophical foundations of internet science, the foundational principles on the nature of the internet are essentially diverse ones - and in many cases they are naïve, 
unconsciously accepted, non-reflective, uncertain, or vague presuppositions (see e.g., [5-14]. Philosophical considerations on the nature of the internet and on the effective principles of internet science can usefully contribute to overcoming these difficulties.

This situation is practically the same as we have (or had) in cases of any kind of sciences: the subject matter and the foundational principles of a scientific discipline are coming from philosophical considerations. As an illustration we can recall the determining role of natural philosophy in the formation of natural sciences, or the role of philosophy of science in the self-consciousness functioning of any developed scientific disciplines.

However, scientific theories of the internet face additional difficulties if they want to reflect on the (pluralistic) postmodern characteristics of the internet. Recently, there is a better chance of producing acceptable treatments of these difficulties in philosophies than in sciences.

Like an internet science, philosophy of the internet also provides a theoretical description of the internet, but it is a completely different theoretical construction - at least if we do not identify philosophy with a kind of linguistic-logic attraction, but we see it traditionally as the conceptual reconstruction of our whole world set up by critical thinking.

As Aristotle declared in his Metaphysics, there are two kinds of theoretical methodologies: the scientific disciplines describe beings from a selected aspect of them, but philosophy describes 'beings as beings' as a whole, considering them from all of their existing aspects. In this tradition, focusing on a given being, discovering and disclosing all of its interrelations of everything else, and in this way, characterizing the being from all of its aspects, the philosopher builds up a complete world in which the given being exists. Philosophical understanding is proceeding on the parallel 'constructions' of the 'being as being' and the 'whole' world. An ontology created in this way is essentially different from the ontologies constructed in computer sciences. Currently, this Aristotelian style of making philosophy is not really fashionable, and, in fact, not so easy to perform, but it seems to be not impossible and perhaps even necessary if one wants to understand a new kind of being of our recent world, as the internet is.

So, the crucial distinction between sciences and philosophy makes clear the different possibilities of science and philosophy in the theoretical description of the internet. Considering further the science-philosophy relationships it becomes obvious that there is no science without philosophy. Historically, (European) philosophy emerged several hundred years before science did; science does not exist without (or prior to) philosophy. Of course, this is absolutely true in case of any concrete disciplines: emerging scientific disciplines are based on and spring out from philosophical (e.g., natural-philosophical) considerations and they include, incorporate, and develop these contents further. What is a natural object? What is a living organism? What is a constitution? And how can we identify and describe their nature and characteristics? Any scientific understanding presupposes such conceptual constructions. However, these procedures sometimes remain hidden, and the given scientific activity runs in an unconscious manner. These situations provide possibilities for the philosophy of science to clarify the real cognitive structures.
Following these intellectual traditions, if we want to construct an internet science, we need some kind of philosophical understanding of the internet prior to the scientific one. What is the internet? What are its most fundamental specificities and characteristics? What are the interrelationships between the internet and all the other beings of our world? Only the philosophical analyses can provide an understanding of the internet as the internet, a theoretical description of its very nature, as a totality of its all aspects, as a whole entity.

These are the reasons that I have proposed for building a philosophy of the internet prior to the scientific theory of it [15-18]. First of all, taking into account the huge amount of its aspects, appearances, modes of use, etc., we should have to understand the nature of the internet and to suggest useful concepts, valid principles, and operable practices for its description. I have proposed to construct a philosophy of the internet in an analog manner as the philosophy of nature (or natural philosophy) was created before (natural) sciences.

However, besides this possibility, there are additional possibilities to contribute to the philosophy of the internet. Realizing the crucial social and cultural impacts of internet use, philosophers have started to consider the influence of internet use on philosophy [19-21,.22-24]. Typically, they focus on a particular aspect or side of the internet or internet use and put it into a philosophical context. In this way - doing research on the 'philosophical problems of the internet' - one can identify the philosophical consequences of some kind of specificity of the internet or can disclose something on the nature of the specificity of the internet. This is the philosophy of the internet making in an analog manner as we used to make research in the philosophy of science or philosophy of language, or philosophy of technology, etc.

In the case of the natural philosophical type of the philosophy of the internet, we should have to create a complete philosophy in order to propose an understanding of the internet in our world, and an understanding of our world which includes the internet. In case of the philosophy of science type of the philosophy of the internet, we should have to apply, improve, or modify an existing philosophy in a sense in order to propose an understanding of a philosophical problem of the internet, and an understanding of a philosophical problem created by the existence and use of the internet. The latter type of philosophy is closer to internet science, while the former approach is closer to a real philosophy of the internet.

As I see it, the so-called philosophy of the Web (Philoweb) initiative is a representative of the 'philosophical problems of the internet' type of research $[19,22]$. The typical analyses in their papers focus on a particular aspect of the internet (or the web) or focus on particular philosophical approaches (e.g., semantics, ontology) and try to conclude several consequences in these contexts.

Another important work in a similar philosophical methodology is provided by Floridi [23, 24]. Floridi's philosophical works, for example, describe the changing meanings of several classical philosophical concepts (like reality) because of the extended internet use and vice versa: internet use is taking place in a non-traditional reality.

Some additional philosophical approaches focus on more specific disciplines (e.g., computer mediated communication, ethics) or 
specific problems (e.g., embodiment, critical theory of technology), etc. [25-28].

Summing up, the philosophy of the internet can be considered as a new field of culture, a recent version of philosophizing with the ambitions to build philosophies in the era of the emergence and deployment of the internet and internet use and taking these new circumstances seriously. It necessarily has different realizations, with different ideologies, values, emphases, cognitive structures, languages, accepted traditions, etc. There are at least two metaphilosophical attitudes toward this new cultural entity: a) creating an original version of philosophy, taking into consideration all of the experiences in the era, b) modifying existing philosophical concepts, systems, approaches, and meanings in order to understand the emerging problems of the internet era.

\section{SPECIFICITIES OF AN 'ARISTOTELIAN' PHILOSOPHY OF THE INTERNET}

In the last 10-15 years, I have developed a natural philosophical type of the philosophy of the internet which I call 'Aristotelian' philosophy of the internet. As an illustration of the abovementioned ambitions, now I will try to sum up its main ideas.

This philosophy of the internet has Aristotelian characteristics in the following sense:

1) It is clear from the history of (natural) sciences that natural philosophy has a priority to any kind of natural sciences. The most successful natural philosophy (or philosophy of nature) was created by Aristotle. In his thinking, a 'division of labor' between philosophy and sciences was clearly declared: understanding the being as being, or understanding an aspect of a being. Historically and logically, in the first step we can 'philosophically' understand a given being and its most essential characteristics, and in a second step, based on this knowledge, we can create a science for their further understanding. In case of the internet, first we try to understand its nature and its most fundamental characteristics 'philosophically, and in the second step, an internet science can be created based on this knowledge.

2) In the Aristotelian view, beings (and the world as well) have a complex nature and for their understanding we have to find a complex methodology. His crucial tool for this purpose was his causal 'theory': everything has four interrelated, but clearly separated, causes - the material, the formal, the efficient, and the final cause. Applying this version of causality, the complex nature of any beings (and the world) can be disclosed. In the case of the internet (as a highly complex network of complex networks) this is a very important possibility for a deeper understanding. Of course, the concrete causal contexts will be different (and more concrete) related to the original Aristotelian ones, so we will use the technological, the communication, the cultural, and the organization contexts to describe the highly complex nature of the internet.

3) There are several additional, but perhaps less crucial, Aristotelian components in my philosophy of the internet. Aristotle made a sharp distinction between natural and artificial beings (especially in his Physics). Based on this distinction the fundamental role of technologies - as creators of the artificial spheres of beings - in the human world is really crucial, so I tried to find a technological (or techno-scientific) implementation for all of the aspects of the internet. Moreover, in the 'solution' of several classical philosophical problems, I followed the Aristotelian traditions - e.g., my interpretation of virtuality (which is an important task in this philosophy of the internet) is based on the Aristotelian ontology.

It is clear at first glance that the internet is an artificial being created mainly from other artificial beings. This means that its philosophical understanding is necessarily based on the philosophical understanding of other beings, so it has necessarily a kind of 'metaphilosophical' characteristic. (Notice that the collection of papers on Philoweb [20] was first published by Monnin and Halpin in the journal Metaphilosophy.) The general view of the Aristotelian causality (in the abovementioned way) can be considered as a metaphilosophical tool, which presupposes to understand and use philosophies of technology, philosophies of communication, philosophies of culture, and philosophies of organization for producing a complex philosophy of the internet. Additionally, it is useful to study and use the philosophical views on information, reality and virtuality, community, system and network, modern and postmodern, knowledge, human nature, spheres of human being, etc., in the process of constructing the philosophy of the internet.

As is clear from the statements above, this philosophy of the internet is not just about an abstract description of the internet, since it is included in and coexists with natural, human, social, and cultural entities in a complex human world. According to our research strategy, first, we examine the complex nature of the internet, and then we can analyze the social and cultural impacts of its use.

\section{ON THE NATURE OF THE INTERNET}

In the 'natural philosophical type' or the Aristotelian philosophy of the internet, the main task is to understand the nature of the internet and some of its essential characteristics. Below, a short outline of the components of this philosophy is presented in the form of theses. (For a more detailed discussion of the philosophical issues involved, see [15] or its online English translation [18].)

In the Aristotelian philosophy of the internet, we conceive of the internet in four - easily distinguishable, but obviously connected - contexts: we regard it as a system of technology, as an element of communication, as a cultural medium, and as an independent organism.

1) Technological context. I propose that we conceive of technology as a specific form or aspect of human agency, the realization of human control over a technological situation. In consequence of the deployment of this human agency, the course and the outcome of the situation seem no longer governed by natural constraints but by specific human goals. Human control of technological situations yields artificial beings as outcomes. With the use of technology, man can create and maintain artificial entities and, as a matter of fact, an artificial world: its own "not naturally given" world and she/he shapes her/his own nature through her/his own activity. Every technology is value-laden - i.e., technologies are not neutral; they unavoidably express, realize, and distribute their built-in values during usage. The internet obviously is a technological product, and at the same time it is a consciously created technological system, so, like other technologies, the internet also serves human control over given situations. 
However, the internet is a specific system of technology; it is an information technological system. Information is created through interpretation, so a certain kind of hermeneutical practice is a decisive component of information technologies. In consequence, information - and all kinds of information 'products' - is virtual by nature. Virtuality is a kind of reality, a reality with a measure, a kind of reality which has no absolute character, but which has a relative nature [29].

Thus, from a technological point of view, the internet is an artificially created and maintained virtual sphere, for the operation of which the functioning of the computers connected into the network and the concrete practices of people's interpretations are equally indispensable.

2) Communication context. For the characterization of the internet as an element of communication, we can understand communication as a certain type of technology, the goal of which is to create and maintain communities. Consequently, the technologies of communication used on the internet are those technologies with the help of which particular - virtual, open, extended, online, etc. communities can be built. The individual relationships to the communities that can be built, and the nature of the communities can be completely controlled through technologies of the internet (e-mail, chat, lists, blogs, podcast, social networks, etc.).

Thus, as regards communication, the internet is the network of consciously created and maintained extended plural communities, for the functioning of which the harmonized functioning of computers connected to the network as well as the individual's control over his own communicative situations are needed.

3) Cultural context. From a cultural point of view, the internet is a medium which can accommodate, present, and preserve the wholeness of human culture - both as regards quality and quantity. It can both represent a whole cultural universe and different, infinitely varied cultural universes (worlds).

Culture is the system of values present in coexisting communities; it is 'the world of' communities. Culture is the technology of world creation. Culture shapes and also expresses the characteristic contents of a given social system. Each social system can be described as the coexistence of human communities and the cultures they develop and follow. Schematically, society $=$ communities + cultures.

The internet accommodates the values of the late modern age, or the 'end' of modernity. That is, it houses late modern worlds. Late modern culture contains modern values as well, but it refuses their exclusivity and it favors a plural, postmodern system of values. The way of producing culture is essentially transformed: the dichotomy of experts creating traditional culture and the laymen consuming it are replaced by the 'democratic nature' of cyber culture: each individual produces and consumes at the same time.

Thus, from a cultural point of view, the internet is a network of virtual human communities, artificially created by man unsatisfied by the world of modernity; it is a network in which a postmodern system of values based on the individual freedom and independence of cyberculture prevails.

4) Organism context. From an organizational point of view, the internet is a relatively independent organism, which develops according to the conditions of its existence and the requirements of the age. It is a (super)organism created by the continuous activity of people, the existence, identity, and integrity of which is unquestionable; systems, networks, and worlds penetrating each other are interwoven in it. It has its own, unpredictable evolution: it develops according to the evolutionary logic of creation and human being, wishing to control its functioning, is both a part and a creator of the organism.

The indispensable vehicles are the net, built of physically connected computers, the web, stretching upon the links which connect the content of the websites into a virtual network, the human communities virtually present on the websites organized into social networks, the interlinked human things as well as the infinite variations of individual and social cultural entities and cultural universes penetrating each other.

The worldwide organism of the internet is imbued with values: its existence and functioning constantly creates and sustains a particular system of values: the network of postmodern values. The non-hierarchically organized value sphere of virtuality, plurality, fragmentation, included modernity, individuality, and opposition to power, interconnected through weak bonds, it penetrates all activity on the internet - moreover, it does so independently of our intentions, through mechanisms built into the functioning of the organism.

Thus, from the organizational point of view, the internet is a superorganism made of systems, networks, and cultural universes. Its development is shaped by the desire of late modern man to 'create a home,' entering into the network of virtual connections impregnated with the postmodern values of cyberculture. For human beings, the internet is a new - more homely - sphere of existence; it is the exclusive vehicle of web-life. Web-life is created through the transformation of 'traditional' communities of society and the cultures prevailing in the communities. Schematically, web-life = 'online' communities + cybercultures.

\section{CONCLUSION}

To sum up, the internet as a whole entity is the medium of a new form of existence created by late modern man, a form that is built on earlier (natural and social) spheres of existence, and yet it is markedly different from them. We call this newly formed existence web-life, and our goal is to understand its characteristics.

\section{REFERENCES}

[1] A Short History of the Internet. Retrieved May 10, 2021 from https://www. internetsociety.org/internet/history-internet/

[2] Hobbes' Internet Timeline 25. Retrieved May 10, 2021 from https://www.zakon. org/robert/internet/timeline/

[3] Living Internet. Retrieved May 10, 2021 from https://www.livinginternet.com/

[4] László Ropolyi. 2018. Toward a Philosophy of the Internet. APA Newsletter on Philosophy and Computers 17, 2 (Spring 2018), 40-49.

[5] Ulf-Dietrich Reips and Michael Bosnjak. (eds.). 2001. Dimensions of Internet Science. Pabst Science Publisher. Lengerich.

[6] Panayiota Tsatsou. 2014. Internet Studies: Past, Present and Future Directions. Ashgate. Farnham.

[7] Manuel Castells. 2000. The Rise of The Network Society. (2nd ed.) Blackwell. Oxford.

[8] Manuel Castells. 2001. The Internet Galaxy: Reflections on the Internet, Business, and Society. Oxford University Press. New York.

[9] Barry Wellman and Caroline Haythornthweaite. (eds.). 2002. The Internet in Everyday Life. Blackwell. Oxford.

[10] Albert-László Barabási. 2002. Linked: The New Science of Networks. Perseus Books. Cambridge.

[11] Albert-László Barabási. 2016. Network Science. Cambridge University Press. Cambridge. http://networksciencebook.com/ 
[12] Maria Bakardjieva. 2005. Internet Society. The Internet in Everyday Life. Sage. London.

[13] Lawrence Lessig. 2006. Code version 2.0. Basic Books. New York.

[14] Christian Fuchs. 2008. Internet and Society. Social Theory in the Information Age. Routledge. London, New York.

[15] László Ropolyi. 2006. Az Internet természete. Internetfilozófiai értekezés. (in Hungarian) (On the Nature of the Internet. Discourse on the Philosophy of the Internet). Typotex. Budapest.

[16] László Ropolyi. 2007. Shaping the Philosophy of the Internet. In S. Kaneva (ed.) Philosophy Bridging Civilizations and Cultures. IPhR - BAS. Sofia. 329-334.

[17] László Ropolyi. 2010. Shaping the third mode of human existence on the Internet. Extended abstract: 3 . ICT\&S Meeting - Theorising the Internet - Paper n. 5: Shaping the third mode of human existence on the Internet, tripleC. 8, 2 (2010), 133-135. http://triple-c.at/index.php/tripleC/article/view/221/175

[18] László Ropolyi. 2013. Philosophy of the Internet. A Discourse on the Nature of the Internet. Budapest: Eötvös Loránd University. 2013. Retrieved May 10, 2021 from https://regi.tankonyvtar.hu/en/tartalom/tamop412A/2011-0073 philosophy_of_the_internet/index.html. Or as a downloadable pdf document Retrieved May 10, 2021 from http://www.eltereader.hu/kiadvanyok/philosophyof-the-internet

[19] Harry Halpin. 2008. Philosophical Engineering: Towards a Philosophy of the Web. APA Newsletter on Philosophy and Computers. 7, 2 (Spring 2008), 5-11.
[20] Alexandre Monnin and Harry Halpin. 2012. Toward a Philosophy of the Web: Foundations and Open Problems. Metaphilosophy. 43, 4 (July 2012), 361-379.

[21] Alexandre Monnin and Harry Halpin. 2014. Toward a Philosophy of the Web: Foundations and Open Problems. in [22] 1-20.

[22] Harry Halpin and Alexandre Monnin. (eds.). 2014. Philosophical Engineering. Toward a Philosophy of the Web. Wiley Blackwell. Chichester/Malden/Oxford.

[23] Luciano Floridi. 2014. The Fourth Revolution: How the Infosphere Is Reshaping Human Reality. Oxford University Press. Oxford.

[24] Luciano Floridi. (ed.). 2015. The Onlife Manifesto. Being Human in a Hiperconnected Era. Springer. New York

[25] Charles Ess. (ed.). 1996. Philosophical Perspectives on Computer-Mediated Communication. State University of New York Press. Albany.

[26] Charles Ess. 2013. Digital Media Ethics. Revised and updated second edition Polity Press. Cambridge, Malden, MA.

[27] Hubert Dreyfus. 2009. On the Internet. (2nd ed.) Routledge. London and New York.

[28] Andrew Feenberg and Norm Friesen. (eds.). 2011. (Re)Inventing the Internet: Critical Case Studies. Sense Publishers. Rotterdam.

[29] László Ropolyi. 2016. Virtuality and Reality-Toward a Representation Ontology. Philosophies 1, 1 (2016), 40-54. 